\title{
Cloning and expression of the 1-aminocyclopropane-1-carboxylic oxidase gene from Agrostis stolonifera
}

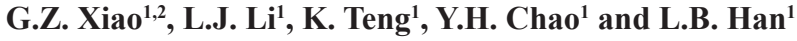 \\ ${ }^{1}$ Turfgrass Research Institute, College of Forestry, Beijing Forestry University, \\ Beijing, China \\ ${ }^{2}$ College of Horticulture and Garden, Yangtze University, Jingzhou, China \\ Corresponding authors: Y.H. Chao / L.B. Han \\ E-mail: chaoyuehui@163.com / hanliebao@163.com
}

Genet. Mol. Res. 15 (4): gmr15049034

Received July 26, 2016

Accepted September 12, 2016

Published November 3, 2016

DOI http://dx.doi.org/10.4238/gmr15049034

Copyright (C) 2016 The Authors. This is an open-access article distributed under the terms of the Creative Commons Attribution ShareAlike (CC BY-SA) 4.0 License.

\begin{abstract}
A gene encoding 1-aminocyclopropane-1-carboxylic oxidase (ACO), which catalyzes the terminal step in ethylene biosynthesis, was isolated from Agrostis stolonifera. The AsACO gene is composed of $975 \mathrm{bp}$, encoding 324 amino acids. Three exons interspersed by two introns form $A s A C O$ gDNA. A BLAST search of the nucleotide sequence revealed a high level of similarity (79-91\%) between $A s A C O$ and $A C O$ genes of other plants. A phylogenetic tree was constructed via BLAST in the NCBI, and revealed the highest homology with wheat TaACO. The calculated molecular mass and predicted isoelectric point of $A s A C O$ were 36.25 and $4.89 \mathrm{kDa}$, respectively. Analysis of subcellular localization revealed that $A s A C O$ is located in the nucleus and cytoplasm. The Fe(II)-binding cofactors and cosubstrate were identified, pertaining to the $A C O$ family. The expression patterns of $A s A C O$ were determined by quantitative real
\end{abstract}

Genetics and Molecular Research 15 (4): gmr15049034 
time PCR. AsACO expression was highest in the stem, and was strongly up-regulated in response to ethephon, methyl jasmonate, salicylic acid, and cold temperature, but down-regulated in response to drought and $\mathrm{NaCl}$ treatment. The protein encoded by $A s A C O$ exhibited ACC oxidase activity in vitro. Taken together, these findings suggest that $A s A C O$ contains domains common to the $A C O$ family, and is induced in response to exogenous hormones. Conversely, some abiotic stress conditions can inhibit AsACO expression.

Key words: AsACO; Agrostis stolonifera; Ethylene biosynthesis; Abiotic stress

\section{INTRODUCTION}

Ethylene is one of the most important gaseous phytohormones in plants, and is involved in many physiological processes. Signaling regulated by ethylene is involved in plant growth, including seed germination, flower and leaf formation, sexual development, fruit ripening, and senescence (Bleecker and Kende, 2000). Ethylene biosynthesis has been demonstrated to play a crucial role not only in plant development, but also in stress tolerance (Yang and Hoffman, 1984; Binnie and McManus, 2009). Therefore, studies have investigated the mechanisms of ethylene production and manipulated the amount of ethylene produced, thus increasing plant vigor and stress tolerance (Ski and Ska, 2005; Han et al., 2011). The results of studies on rice have shown that ethylene application can improve drought-resistant traits (Wan et al., 2011). It has been elucidated that 1-aminocyclopropane-1-carboxylate synthase (ACS) functions in the first step of ethylene biosynthesis and can enhance drought tolerance and inhibit drought-induced senescence in maize (Young et al., 2004). It has also been reported that selected strains of Ocimum sanctum containing ACC deaminase tolerate waterlogging stress by reducing ethylene generation (Barnawal et al., 2012). ACS catalyzes the conversion of S-adenosylmethionine (AdoMet) to $A C C$. Then, 1-aminocyclopropane-1-carboxylic acid oxidase (ACO) converts ACC to ethylene in the ethylene biosynthesis pathway (Adams and Yang, 1979). By regulating ethylene biosynthesis in advanced plant species; the $A C O$ gene may play an auxiliary or major role in this process. (Ruduś et al., 2013).

$\mathrm{ACO}$ is classified as a member of a non-heme oxygenase family, in which ferrous is indispensable and 2-oxoglutarate (2OG) serves as a cosubstrate (Mirica and Klinman 2008). Using bicarbonate as an activator, ACO catalyzes the oxidation of ACC, producing ethylene, $\mathrm{CO}_{2}$, and hydrogen cyanide (Zhang et al., 2004). Using molecular cloning and heterologous expression, $A C O$ can be isolated to homogeneity. ACO is encoded by a divergent multigene family, and modulation of $A C O$ expression differs under different environmental conditions; however, the mechanism of $A C O$ activity requires further study (Kende and Zeevaart, 1997).

Much research has been performed to isolate and utilize the $A C O$ gene in dicotyledons, such as apple (Binnie and McManus, 2009), melon (Lasserre et al., 1996), white clover (Chen and McManus, 2006), and the model organism Arabidopsis thaliana (Babula et al., 2006). However, limited studies have been performed using monocotyledonous plants such as Agrostis stolonifera, to explore the mechanisms controlling ethylene biosynthesis.

A. stolonifera is a very common cool-season grass used extensively for golf courses and residential lawns (Zhang, et al., 2003). However, the stoloniferous growth habit of $A$.

Genetics and Molecular Research 15 (4): gmr15049034 
stolonifera can result in excessive thatch formation, engendering poor rooting, reduced water uptake, and pathogen infection. The purpose of the present study was to determine how hormones and $\mathrm{NaCl}$ stress affect expression of $A s A C O$ by isolating and cloning a fulllength cDNA encoding $A C O$ from $A$. stolonifera leaf. qRT-PCR techniques were used to examine $A s A C O$ expression in different parts of the plant and to determine the response to ethephon (Et), methyl jasmonate (MeJa), salicylic acid (SA), abscisic acid (ABA), and $\mathrm{NaCl}$ stress. Furthermore, the subcellular location and expression patterns were studied by transient expression. This study on the $A s A C O$ gene may lay a theoretical foundation for future studies on ethylene regulation and transgenic breeding.

\section{MATERIAL AND METHODS}

\section{Plant materials}

The A. stolonifera cultivar Penncross and Nicotiana benthamiana seeds, preserved in the laboratory, were planted in mixed aggregate general-purpose plant growth medium, including coarse perlite, vermiculite, and peat in a 1:1:1 ratio. Plants were grown in a growth chamber, and treated under the following conditions: average day/night temperature of $22^{\circ} \pm$ $1 / 16 \pm 1{ }^{\circ} \mathrm{C}$, relative humidity $55-60 \%, 14$-h photoperiod of $120 \mathrm{mmol} \cdot \mathrm{m}^{-2} \cdot \mathrm{s}^{-1}$ par, and were fertilized weekly with half-strength Hoagland's (Hoagland and Arnon, 1950) solution.

\section{Isolation of $A s A C O$}

Total RNA was extracted from 3-month-old Penncross leaves using the Trizol (Tiangen Biotech, Beijing, China) method. Genomic DNA was removed by RNase-free DNAse (Tiangen Biotech, Beijing, China) prior to reverse transcription. The reverse transcription reaction involved preheating at $37^{\circ} \mathrm{C}$ for $30 \mathrm{~min}$ in a PCR machine, followed by then performed at $85^{\circ} \mathrm{C}$ for $5 \mathrm{~s}$. cDNA concentration was measured by spectrophotometric measurement. cDNA concentration was measured by spectrophotometric measurement. Hordeum vulgare ACO2a (GenBank: JX046058), Triticum aestivum ACO (GenBank: KF900070), Oryza sativa ACO (GenBank: AF049889), and Zea mays ACO (GenBank: NM_001136755) were used at the test standards. The common conserved sequence was identified and degenerate primers were designed accordingly (Table 1).

\begin{tabular}{|c|c|c|}
\hline Name of primer & Sequence (5'-3') & Purpose of primer \\
\hline 5'-RACE & TCATCACTTGCCTGTAGTGGTCG & 5'RACE-PCR \\
\hline 3'-RACE & CAGGGAGGACAGGTTCAAGGAGTT & 3'RACE-PCR \\
\hline \multirow[t]{2}{*}{$A s A C O$-cDNA } & F: ATAGCGAGAGGGCCGGAGAGAGAGA & \multirow[t]{2}{*}{ RT-PCR of $A s A C O$ cDNA } \\
\hline & R: GATCGACTGTCACTGATCGATCAGG & \\
\hline \multirow[t]{2}{*}{$A s A C O$-gDNA } & F: TATAGCGAGAGGGCCGGAGAGAGAG & \multirow[t]{2}{*}{ RT-PCR of $A s A C O$ gDNA } \\
\hline & R: GATCGACTGTCACTGATCGATCAGG & \\
\hline \multirow[t]{2}{*}{ AsACO-RT } & F: CAGGGAGGACAGGTTCAAGGAGTT & \multirow[t]{2}{*}{ Real time-PCR analysis of $A s A C O$ gene } \\
\hline & R: GAATTCCTTCATCACTTGCCTGTAG & \\
\hline \multirow{2}{*}{$\begin{array}{l}\text { AsActin-RT } \\
\text { (GenBank: JX644005.1) }\end{array}$} & F: TTGAACCCAAAAGCCAACAG & \multirow{2}{*}{$\begin{array}{l}\text { Real time-PCR of Agrostis stolonifera actin gene } \\
\text { used as internal control }\end{array}$} \\
\hline & R: CCAGCAAGATCCAAACGAAG & \\
\hline \multirow[t]{2}{*}{$3302 Y-A s A C O$} & F: cacgggggactcttgaccatggtaATGGCGACTGCAGCAGCTG & \multirow[t]{2}{*}{ Subcellular localization vector of $A s A C O$} \\
\hline & R: ggtacacgcgtactagtcagatcGGCCGTGGCGATGGGCGCG & \\
\hline \multirow[t]{2}{*}{$3302 \mathrm{SP} 6-A s A C O$} & F: gacactatagaacagaccaccATGGCGACTGCAGCAGCTG & \multirow[t]{2}{*}{ Sp6-3xFlag vector of $A s A C O$} \\
\hline & R: tccttgtaatccagatctacGGCCGTGGCGATGGGCGCG & \\
\hline \multirow[t]{2}{*}{ SP6- $A s A C O$} & F: CTTGATATTTAGGTGACACTATAGA & \multirow[t]{2}{*}{ Analysis of AsACO protein } \\
\hline & R: TTATATGATAATCATCGCAAGACCG & \\
\hline
\end{tabular}

Genetics and Molecular Research 15 (4): gmr15049034 
Utilizing the sequence as a template, $A s A C O$ was cloned by 5'- and 3'-RACE to obtain the full coding sequence (CDS) according to the manufacturer instructions (SMARTer RACE 5'- and 3'- Kit, TaKaRa, Dalian, China) at an annealing temperature of $57^{\circ} \mathrm{C}$. PCR products were cloned using a pMD19-T vector (TaKaRa) and subsequently sequenced at the Beijing Genomics Institute (Beijing, China).

Amplification of the full-length $A s A C O$-cDNA was performed using $A s A C O-\mathrm{F}$ and $A s A C O$-R, obtained using primers and cDNA as templates. AsACO-gDNA was obtained by utilizing DNA as a template, $A s A C O-\mathrm{F}$, and $A s A C O$-R were used as primers. Next, the intronexon structure of $A S A C O$ was determined.

\section{Bioinformatic and sequence analysis}

Comparison of homologous sequences was performed using the DNAMAN software (v. 8.0). Homologue similarity was analyzed using BLAST in the NCBI database. An unrooted phylogenetic tree was generated by the neighbor-joining method using MEGA v. 5.0. Onethousand bootstrap replicates were used to ensure stability of the tree branch. The isoelectric points (pI) and molecular weights (MW) were predicted using the compute pI/MW tool (http://web.expasy.org/compute_pi/). Underlying sites and the existence of signal peptide cleavage sites were identified by SignalP 4.1 Server (http://www.cbs.dtu.dk/services/SignalP/) (Petersen et al., 2011). Subcellular localization of $A s A C O$ was determined and its level of expression was identified by analyzing the protein sequence through ProtComp v. 9.0 (http:// www.softberry.com).

\section{Analysis of $A s A C O$ gene induction}

Gene expression was analyzed in 3-month-old seedlings, which were cultured in a growth chamber and then anatomized into root, stem, new leaf, and old leaf. To examine the effects of plant hormones and abiotic stress on the expression of $A s A C O, 3$-month-old seedlings were treated with $10 \mu \mathrm{M} \mathrm{Et}, 10 \mu \mathrm{M}$ MeJA, $10 \mu \mathrm{M}$ ABA (Teng et al. 2016), $50 \mathrm{mM}$ SA, cold temperature $\left(4^{\circ} \mathrm{C}\right)$, drought $(30 \%$ PEG6000), and $200 \mathrm{mM} \mathrm{NaCl}$. Expression of the $A s A C O$ gene in the shoot was measured at selected points over a 24 -h period $(0,1,3,6,12$, and $24 \mathrm{~h}$ ). AsACO-RT and AsActin-RT were used as primers (Table 1). Each qRT-PCR was performed in a 96-block-RT-PCR system (CFX Connect, BIO-RAD, Hercules, CA, USA) with an initial $12.5 \mu \mathrm{L}$ UltraSYBR Mixture (CoWin, Beijing, China) in a final $25-\mu \mathrm{L}$ volume, under the following conditions: $15 \mathrm{~s}$ denaturation at $94^{\circ} \mathrm{C}$ and $1 \mathrm{~min}$ annealing at $68^{\circ} \mathrm{C}$ for 40 cycles. The endogenous gene AsActin (GenBank: JX644005.1) was used in the comparative $\mathrm{C}_{\mathrm{T}}\left(2^{-\Delta C \mathrm{~T}}\right)$ method, in which $\Delta \mathrm{G}_{\mathrm{T}}=\mathrm{C}_{\mathrm{T} \text { (target gene) }}-\mathrm{C}_{\mathrm{T}(\text { (reference gene) }}$, allowing the relative quantification of gene expression. This equation was improved through the comparative $\Delta \Delta \mathrm{C}_{\mathrm{T}}$ method (Chao et al., 2009). Four independent biological repeats were conducted for each treatment to ensure data accuracy.

\section{Subcellular localization of $A s A C O$}

To generate the CaMV35S:AsACO-YFP construct, the AsACO CDS was amplified using a pair of designed 3302Y-AsACO primers (Table 1), and then subcloned into a BalgII site in CaMV35S on a 3302Y vector (Figure 1a), which was then introduced into EHA105

Genetics and Molecular Research 15 (4): gmr15049034 
agrobacteria using the $\mathrm{CaCl}_{2}$ freeze-thaw method. EHA105 agrobacterium-meditated transformation of $N$. benthamiana (Yang et al., 2000) was followed by 48-h incubation in the dark. The yellow fluorescent protein (YFP) signal and chlorophyll from leaf epidermal cells were examined under a laser confocal microscope (Leica SP-5; Leica, Mannheim, Germany).

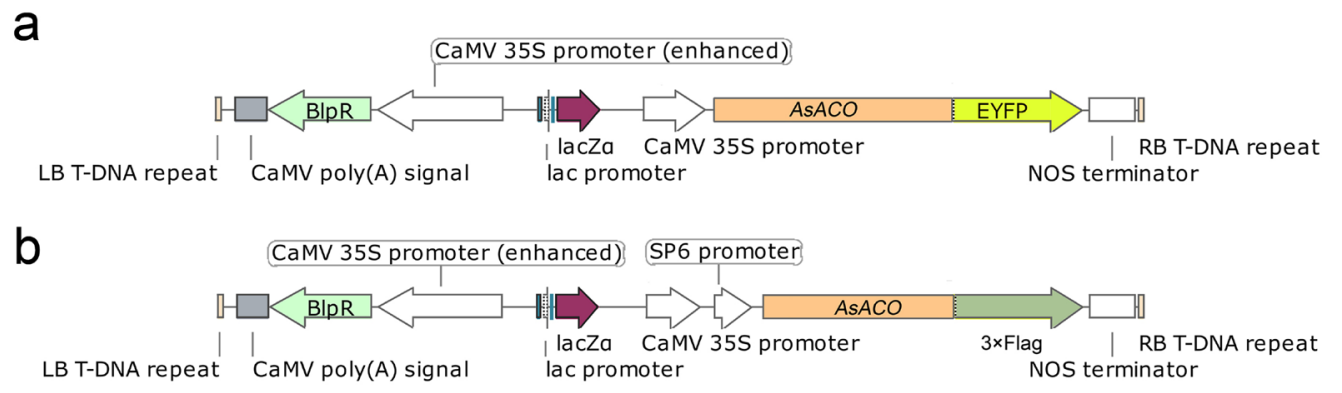

Figure 1. Vector construction of $A s A C O$ for transient expression and AsACO for protein expression. a. vector construction of $A s A C O$ for transient expression, $\mathbf{b}$. vector construction of AsACO for protein expression.

\section{AsACO protein expression and western blot}

To express AsACO protein and generate the SP6:AsACO-Flag construct, the AsACO CDS was amplified using a pair of designed 3302SP6- $A s A C O$ primers (Table 1), and then subcloned into NcoI sites of CaMV35S in a 3302SP6-Flag vector (Figure 1b). The SP6AsACO-Flag CDS was amplified using a pair of designed SP6-AsACO primers (Table 1). The amplified PCR product was introduced into a TNT ${ }^{\circledR}$ SP6 High-Yield Wheat Germ Protein Expression System (Promega Corporation, Madison, WI, USA) following the manufacturer specifications.

The synthesized protein was subjected to Tris-Glycine SDS-PAGE (Sigma Aldrich, St. Louis, MO, USA) using a 5-12\% gradient gel. Briefly, electrophoresis was performed for $20 \mathrm{~min}$ at $60 \mathrm{~V}$ and for $35 \mathrm{~min}$ at $200 \mathrm{~V}$, following which samples were transferred to pure nitrocellulose blotting membrane (Pall Life Sciences, Ann Arbor, MI, USA) for 20 min at 25 $\mathrm{V}$. The blot was blocked with $5 \%$ non-fat dry milk (NFDM) in $1 \mathrm{X}$ TBS $\left(\mathrm{pH} 7.4\right.$ ) at $37^{\circ} \mathrm{C}$ for $1 \mathrm{~h}$ and washed three times with $1 \mathrm{X}$ TBS (pH 7.4) buffer at 5-min intervals. The blot was incubated with monoclonal anti-FLAG M1 primary antibody (Sigma Aldrich) at $10 \mathrm{mg} / \mathrm{mL}$ in $1 \mathrm{X}$ TBS (pH 7.4) in 5\% NFDM solution followed by 1:250 goat anti-mouse IgG peroxidase secondary antibody (Sigma Aldrich) in 5\% NFDM solution. The blots were incubated for 1 $\mathrm{h}$ at $37^{\circ} \mathrm{C}$ in each antibody solution after which the blots were washed with $1 \mathrm{X}$ TBS (pH 7.4) three times for 5 min each (Alkanaimsh et al., 2016).

\section{RESULTS}

\section{Isolation of the $A s A C O$ gene and bioinformatics analysis}

AsACO cDNA (GenBank: KU359229) contained 975 bp and encoded a 324-amino acid AsACO protein (Figure 2). The AsACO gDNA (GenBank: KU921687) sequence contains

Genetics and Molecular Research 15 (4): gmr15049034 
three exons (Figure 3a). After comparison of the protein sequence, N-terminal DIOX-N (nonhaem dioxygenase in morphine synthesis N-terminal) and 2OG-FeII-Oxy [2-oxo-glutarate (2OG) and Fe(II)-dependent oxygenase] (Figure 3b) were identified. Aligning the amino acid sequences of $A s A C O$ with those of TaACO (GenBank: AHJ14562.1), HvACO2a (GenBank: AFO63016.1), and $O b A C O$ (GenBank: XP_006647976.1) identified sequences characteristic of the ACO family The conserved domains of different species were identical by confirming $\mathrm{Fe}(\mathrm{II})$-binding cofactors (His-Xaa-Asp-Xaa-His) and cosubstrate-binding motifs (Arg-XaaSer) (Figure 3c).

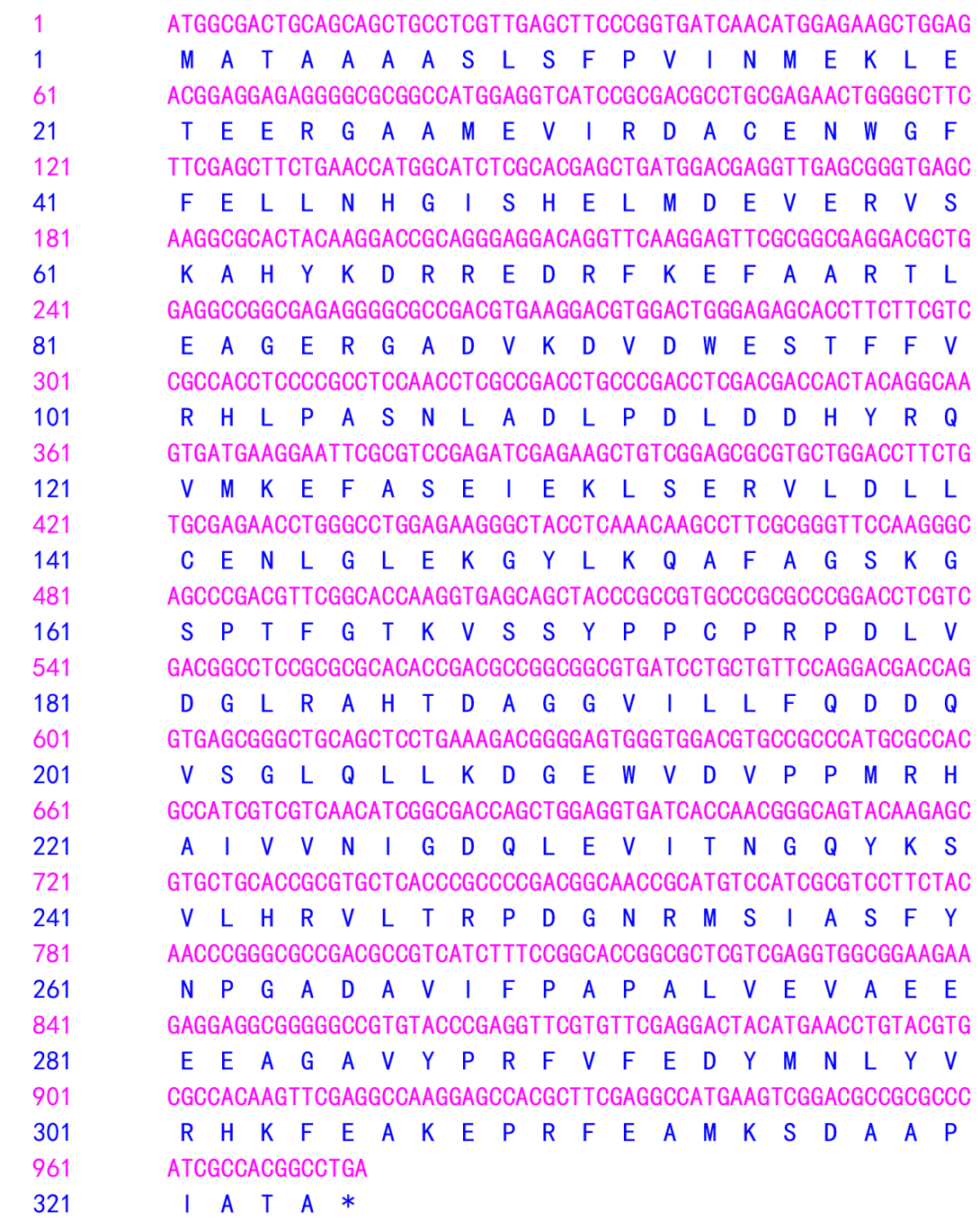

Figure 2. AsACO cDNA sequence from Agrostis stolonifera and the translated amino acid sequence. cDNA was obtained from mRNA extracted from the leaf.

Genetics and Molecular Research 15 (4): gmr15049034 

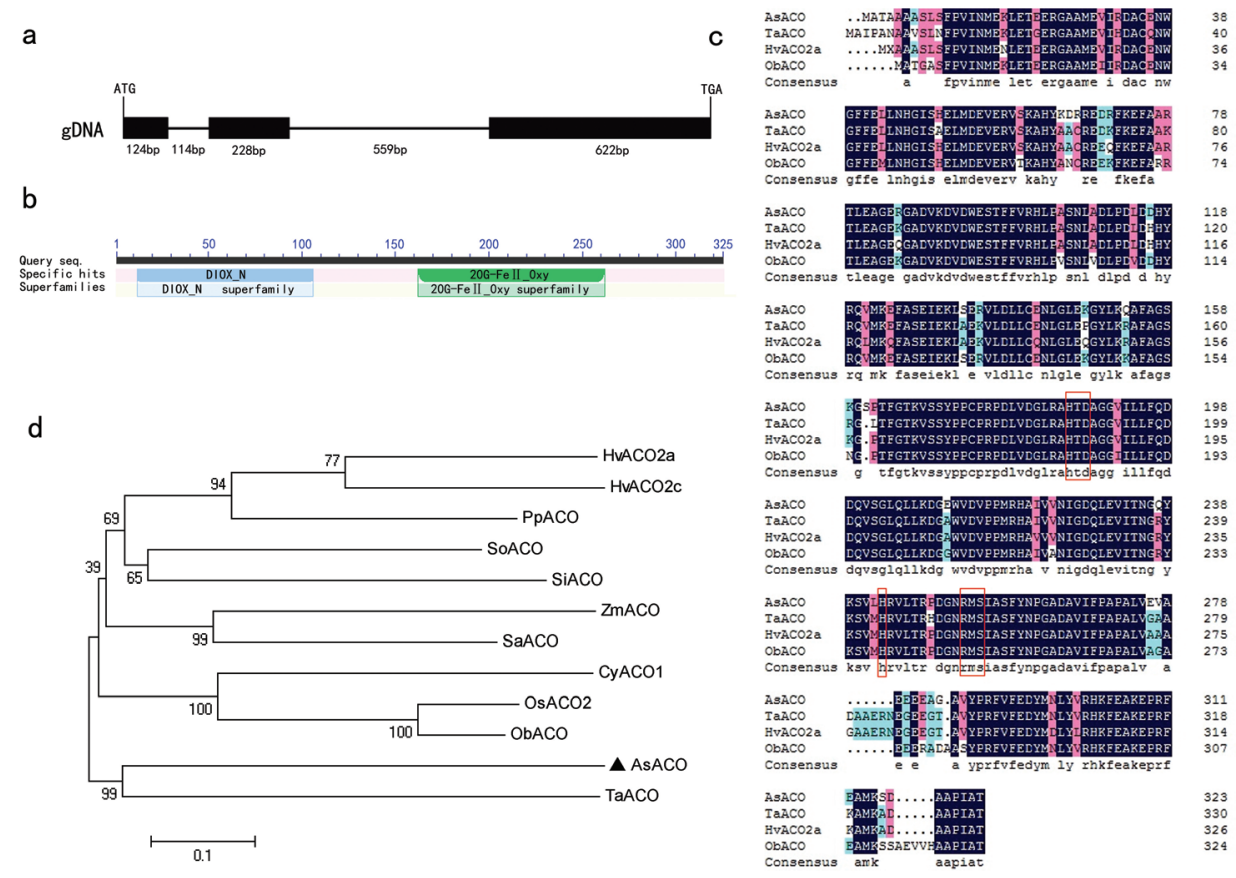

Figure 3. Structure and phylogeny of $A s A C O$. a. $A s A C O$ gDNA sequence. Black boxes represent exons while solid lines represent introns. b. Predicted protein structure of $A s A C O$. DIOX-N: non-haem dioxygenase in morphine synthesis N-terminal; 2OG-Fell_Oxy = 2-oxoglutarate (2OG) and Fe(II)-dependent oxygenase containing domain. c. Rectangular structures represent Fe(II)-binding motifs with a dash, cosubstrate-binding motifs with a continuous dash. In the consensus sequence, black shading represents $100 \%$ identity, pink shading represents $\geq 75 \%$ identity, blue shading represents $\geq 50 \%$ identity. d. Phylogenetic analysis showing homology of the AsACO protein.

The theoretical pI was 4.89 and the calculated MW was $36.25 \mathrm{kDa}$. No signal peptide was predicted by the SignalP 4.1 Server.

\section{Phylogenic analysis}

A phylogenetic tree was used to show the relatedness of the $A C O$ genes based on data from GenBank. Comparison of the different isoforms revealed the highest identity with TaACO of wheat ( $99 \%$ identity). The deduced amino acid sequences also indicated a high degree of homology between $A C O$ (Figure 3d) of other species, such as the GenBank accession Mos of $A s A C O$ are expressed as the following: ObACO: XP_006647976.1; TaACO: AHJ14562.1; HvACO2a: AFO63016.1; HvACO2c: AFO63018.1; OsACO2: AAC05507.1; ZmACO: NP_001130227.1; PpACO: BAB32502.1; SaACO: ABM74187.1; CyACO1: BAF36562.1; SoACO: ACH99202.1; and SiACO: XP_004956979.1.

\section{Pattern of $A s A C O$ expression}

qRT-PCR was performed to determine how $A s A C O$ expression varies in different 
plant tissues, in response to plant hormones, and abiotic stress (Figure 4). High expression levels were observed in stems, and other parts, such as the roots, new leaves, and old leaves were also examined (Figure 4a). The content of $A s A C O$ increased rapidly within the first hour of Et exposure, peaking 1.5-fold higher than the amount in the control. Conversely, after 1 $\mathrm{h}$, expression was inhibited (Figure 4b). Notably, the $A s A C O$ expression began to increase at $3 \mathrm{~h}$ and peaked with a 4.6-fold enhancement $6 \mathrm{~h}$ after induction with MeJa (Figure 4c). Transcription of $A s A C O$ was induced slowly within $3 \mathrm{~h}$, but then decreased after $12 \mathrm{~h}$ in response to SA treatment (Figure 4d). When exposed to ABA, AsACO expression had no regularity. The expression level of $A s A C O$ was highest around $3 \mathrm{~h}$, whereas expression was suppressed at other time points (Figure 4e). AsACO expression was augmented from $3 \mathrm{~h}$, when a peak 2.3-fold increase was observed, to $6 \mathrm{~h}$ in response to cold stress (Figure 4f). However, $A s A C O$ expression was inhibited in response to drought (Figure 4g). The expression of $A s A C O$ was only 0.11 -fold that of the control at $6 \mathrm{~h}$, and was thus significantly suppressed in response to salinity stress (Figure $4 \mathrm{~h}$ ).
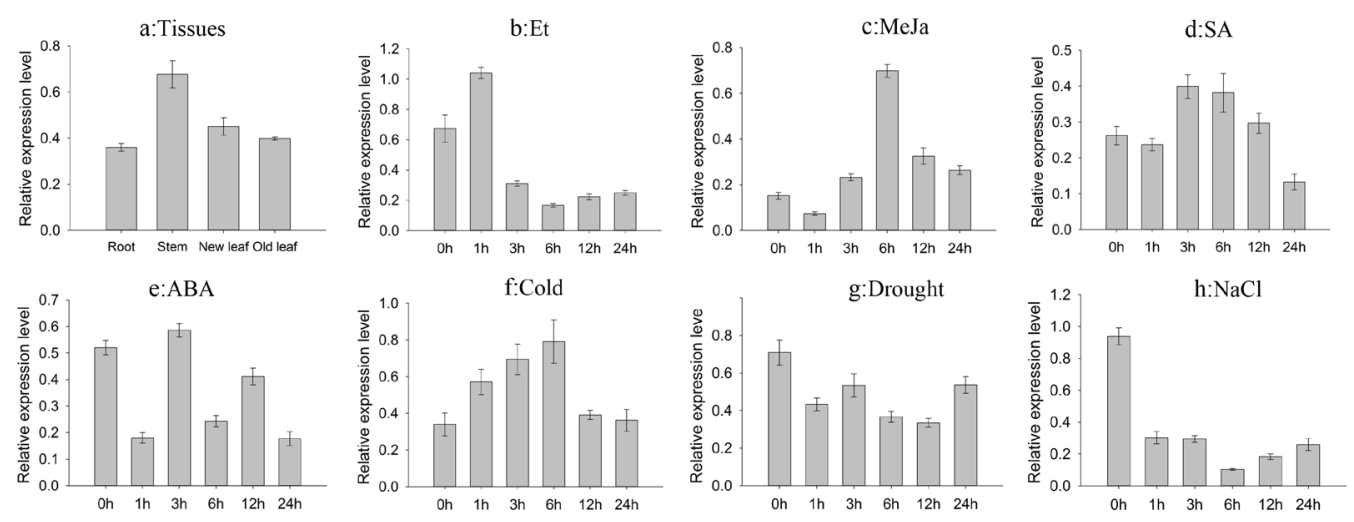

Figure 4. Transcription behavior of $A s A C O$ under different abiotic stress. a. AsACO expressed in different parts of plant tissues; b. $A s A C O$ expression is induced by $10 \mu \mathrm{M}$ ethephon (Et) for $0,1,3,6,12,24$, and $48 \mathrm{~h}$; c. $10 \mu \mathrm{M}$ methyl jasmonate (MeJa); d. $50 \mathrm{mM}$ salicylic acid (SA); e. $10 \mu \mathrm{M}$ abscisic (ABA); f. cold; g. drought; and (h.) 200 $\mathrm{mM} \mathrm{NaCl}$. The data represent the means of four replicates. Error bars indicate $\pm \mathrm{SEM}$.

Together, these results suggest that various plant hormones can induce $A s A C O$ expression, particularly MeJA. In addition, the responsiveness of $A s A C O$ to cold stress was observed.

\section{Subcellular localization of $A s A C O$}

Use of the ProtComp v. 9.0 program integral prediction of protein was localized in cytoplasm with score 8.3. Transient expression of AsACO with YFP, and set YFP without $A s A C O$ as a control, with virus $35 \mathrm{~S}$ serving as drive into $N$. benthamiana. Under UV light, YFP fluorescence was observed in the whole cell (Figure 5a), while the AsACO-YFP fusion protein was localized to the nucleus and cytoplasm but not in the chloroplast, which was observed when the images were merged (Figure 5b).

Genetics and Molecular Research 15 (4): gmr15049034 


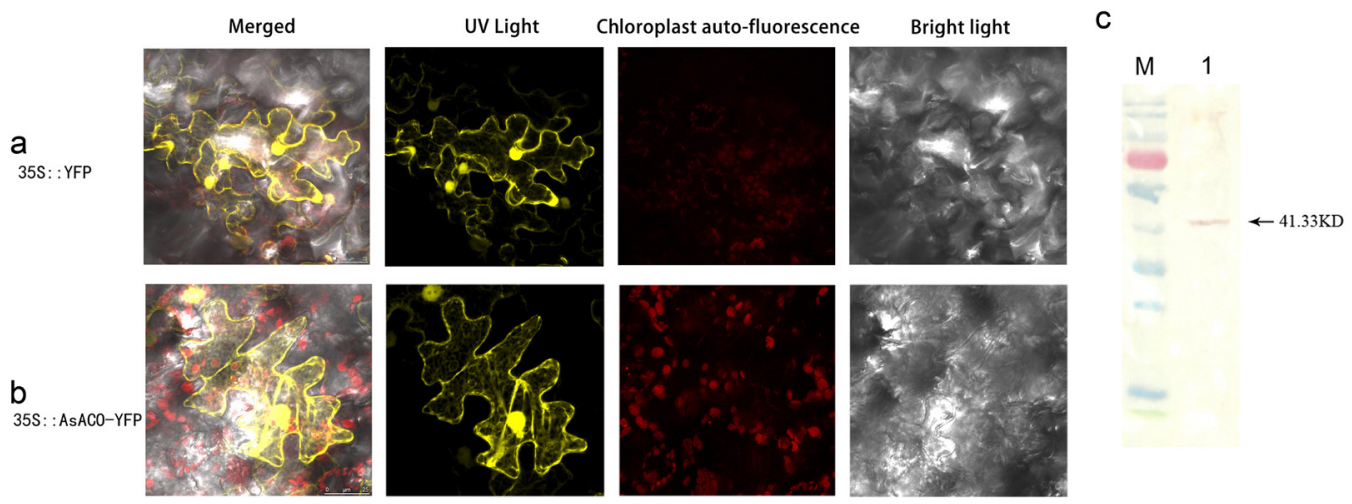

Figure 5. Subcellular distribution of AsACO in the leaf of Nicotiana benthamiana and AsACO protein detection by western blot. 35S::YFP (control) (a) and 35S::AsACO-YFP (b) were transiently expressed in leaf of $N$. benthamiana, and western blot of Flag-fused AsACO (c), probed with an anti-Flag antibody.

\section{Western blot analysis}

To confirm expression of the AsACO protein, we expressed a Flag-tag fusion protein in a wheat germ protein expression system. Recombinant protein expression was confirmed by western blotting using samples from the wheat germ protein expression system and an anti-Flag antibody. The molecular mass of the recombinant protein was $41.33 \mathrm{kDa}$ (Figure $5 \mathrm{c})$. The results of the western blot demonstrated that AsACO exhibits ACC oxidase activity in vitro.

\section{DISCUSSION}

External signals as well as growth signals can contribute to the regulation of ethylene production (Wang et al., 2002). Studies have been performed to determine how $A C O$ functions in the regulation of ethylene production in many dicotyledons such as tomato (Hamilton et al., 1990) and papaya (López-Gómez et al., 2009); however, studies on monocotyledons are limited. Therefore, the present study aimed to investigate this gene from A. stolonifera.

After isolation and sequence comparison, cDNA of the AsACO gene was found to be 975-bp long, encoding 324 amino acids, with a calculated molecular mass of $36.25 \mathrm{kDa}$. The fact that a polypeptide with a length of 300-300 amino acids and a mRNA sequence of 918$1002 \mathrm{bp}$, constitutes a $A C O$ protein of 35-40 kDa (Alexander and Grierson, 2002) supports our finding. The AsACO protein contains three exons. However, the ACO gene is usually composed of four exons, with three interspersed introns. Located near the downstream part of the 5'-UTR, exon 1 has a varying length of $\sim 100 \mathrm{bp}$, along with $\sim 200 \mathrm{bp}$ for exon 2 , and $\sim 300$ bp for exon 3. Exon 4, consisting of $\sim 300 \mathrm{bp}$, is adjacent to the 3'-UTR (Ruduś et al., 2013). A three-exon structure was also observed in A. thaliana AtACO1, Dianthus caryophyllus DcACO, and Z. mays AmACO35 (Ruduś et al., 2013).

The Fe(II)-binding cofactors (His-Xaa-Asp-Xaa-His) and cosubstrate (Arg-Xaa-Ser) were highly conversed in the $A C O$ family domain. $A C O$ sequences of species such as melon and petunia were also found to have the same amino acids conserved across all members of the 
Fe/ascorbate-dependent dioxygenase family (Tang et al., 1993; Zarembinski and Theologis, 1994). Phylogenetic analysis revealed that $A s A C O$ has the highest identity to $T a A C O$, which also belongs to monocotyledons.

As for the AsACO expression level, several studies have shown that $A C O$ is upregulated under various abiotic stresses including temperature, cutting, and oxygen deprivation, and biotic stress caused by pathology. (Moeder et al., 2002; Nie et al., 2002; Pan and Lou, 2008). Ethylene levels have been demonstrated to be increased in response to ethephon (Liu and Reid 1992). After treated by MeJa, the peak of ethylene releasing occurred in advance (Han et al., 2011). As expected, the level of ethylene increased dramatically by $1 \mathrm{~h}$ in response to ethephon and at around $6 \mathrm{~h}$ in response to MeJa treatment. However, it declined sharply afterwards when the exogenous stresses were reduced. Previous studies have reported that SA can inhibit ethylene production by blocking the conversion from 1-aminocyclopropane-1carboxylic acid (Leslie and Romani, 1986). Interestingly, expression of the $A C O$ gene was upregulated, suggesting that ethylene production was accelerated. Further investigation is needed to support this mechanism. Exogenous ABA treatment induced the expression of both $A C S$ and $A C O$ genes, stimulating ethylene production (Zhang et al., 2009). Studies investigating abiotic treatments showed that cold stress induced the up-regulation of $A C O$ gene expression, and the results of the present study were consistent with those findings. However, in our study, expression of $A s A C O$ was found to be severely inhibited by drought and $\mathrm{NaCl}$ stress, which was consistent with the response of $\mathrm{TaACO}$ under drought and $\mathrm{NaCl}$ treatment (Chen et al., 2014). This could be explained by salt-stress inducing an increase in $A C C$ expression, which was higher in salt-tolerant, whereas a decrease in $A C C$ conversion to ethylene, suggesting a reduction in $A C C$ oxidase activity (Lutts et al., 1996). Analysis of subcellular localization suggested that $A s A C O$ is localized in the nucleus and cytoplasm, which is consistent with that observed for TaACO (Chen et al., 2014). Western blot analysis was performed in a wheat germ protein expression system using anti-Flag raised against the gene product of $A s A C O$. The molecular mass of the protein was similar to that of MDACO3 (Binnie and McManus, 2009).

In conclusion, the $A s A C O$ gene is composed of three exons interspersed by two introns and has highest homology to TaACO. The amino acid sequence includes two conversed domains DIOX-N and 2OG-FeII-Oxy, which are consistent with the general characteristics of the $A C O$ family. The expression of $A s A C O$ was up-regulated in response to exogenous hormone treatment, including Et, MeJa, SA, and cold, and down-regulated in response to drought and $\mathrm{NaCl}$ treatment; however, the effect of $\mathrm{ABA}$ on $A s A C O$ expression was not obvious. The protein encoded by the AsACO gene exhibited ACC oxidase activity in vitro. This study provides a foundation for further exploration of how AsACO functions in the process of ethylene biosynthesis in A. stolonifera.

\section{Conflicts of interest}

The authors declare no conflict of interest.

\section{ACKNOWLEDGMENTS}

Research supported by the National High Technology Research and Development Program of China ("863" Program) (\#2013AA102607) and the Science and Technology Program of Shenzhen (\#JCYJ20160331151245672).

Genetics and Molecular Research 15 (4): gmr15049034 


\section{REFERENCES}

Adams DO and Yang SF (1979). Ethylene biosynthesis: Identification of 1-aminocyclopropane-1-carboxylic acid as an intermediate in the conversion of methionine to ethylene. Proc. Natl. Acad. Sci. USA 76: 170-174. http://dx.doi. org $/ 10.1073 /$ pnas. 76.1 .170

Alexander L and Grierson D (2002). Ethylene biosynthesis and action in tomato: a model for climacteric fruit ripening. $J$. Exp. Bot. 53: 2039-2055. http://dx.doi.org/10.1093/jxb/erf072

Alkanaimsh S, Karuppanan K, Guerrero A, Tu AM, et al. (2016). Transient Expression of Tetrameric Recombinant Human Butyrylcholinesterase in Nicotiana benthamiana. Front. Plant Sci. 7: 743. http://dx.doi.org/10.3389/fpls.2016.00743

Babula D, Misztal LH, Jakubowicz M, Kaczmarek M, et al. (2006). Genes involved in biosynthesis and signalisation of ethylene in Brassica oleracea and Arabidopsis thaliana: identification and genome comparative mapping of specific gene homologues. Theor. Appl. Genet. 112: 410-420. http://dx.doi.org/10.1007/s00122-005-0136-7

Barnawal D, Bharti N, Maji D, Chanotiya CS, et al. (2012). 1-Aminocyclopropane-1-carboxylic acid (ACC) deaminasecontaining rhizobacteria protect Ocimum sanctum plants during waterlogging stress via reduced ethylene generation. Plant Physiol. Biochem. 58: 227-235. http://dx.doi.org/10.1016/j.jplph.2014.03.007

Binnie JE and McManus MT (2009). Characterization of the 1-aminocyclopropane-1-carboxylic acid (ACC) oxidase multigene family of Malus domestica Borkh. Phytochemistry 70: 348-360. http://dx.doi.org/10.1016/j. phytochem.2009.01.002

Bleecker AB and Kende H (2000). Ethylene: a gaseous signal molecule in plants. Annu. Rev. Cell Dev. Biol. 16: 1-18. http://dx.doi.org/10.1146/annurev.cellbio.16.1.1

Chao Y, Kang J, Sun Y, Yang Q, et al. (2009). Molecular cloning and characterization of a novel gene encoding zinc finger protein from Medicago sativa L. Mol. Biol. Rep. 36: 2315-2321. http://dx.doi.org/10.1007/s11033-009-9450-5

Chen BC and McManus MT (2006). Expression of 1-aminocyclopropane-1-carboxylate (ACC) oxidase genes during the development of vegetative tissues in white clover (Trifolium repens L.) is regulated by ontological cues. Plant Mol. Biol. 60: 451-467. http://dx.doi.org/10.1007/s11103-005-4813-3

Chen D, Ma X, Li C, Zhang W, et al. (2014). A wheat aminocyclopropane-1-carboxylate oxidase gene, TaACO1, negatively regulates salinity stress in Arabidopsis thaliana. Plant Cell Rep. 33: 1815-1827. http://dx.doi.org/10.1007/ $\underline{\mathrm{s} 00299-014-1659-7}$

Hamilton A, Lycett G and Grierson D (1990). Antisense gene that inhibits synthesis of the hormone ethylene in transgenic plants. Nature 346: 284-287. http://dx.doi.org/10.1038/346284a0

Han M, Zhang T, Zhao C and Zhi J (2011). Regulation of the expression of lipoxygenase genes in Prunus persica fruit ripening. Acta Physiol. Plant. 33: 1345-1352. http://dx.doi.org/10.1007/s11738-010-0668-6

Hoagland DR and Arnon DI (1950). The water-culture method for growing plants without soil. Calif. Agric. Exp. Stn. Circ 347: 357-359.

Kende H and Zeevaart J (1997). The five "classical" plant hormones. Plant Cell 9: 1197-1210. http://dx.doi.org/10.1105/ tpc.9.7.1197

Lasserre E, Bouquin T, Hernandez JA, Bull J, et al. (1996). Structure and expression of three genes encoding ACC oxidase homologs from melon (Cucumis melo L.). Mol. Gen. Genet. 251: 81-90.

Leslie CA and Romani RJ (1986). Salicylic acid: A new inhibitor of ethylene biosynthesis. Plant Cell Rep. 5: 144-146. http://dx.doi.org/10.1007/BF00269255

Liu JH and Reid D (1992). Auxin and ethylene-stimulated adventitious rooting in relation to tissue sensitivity to auxin and ethylene production in sunflower hypocotyls. J. Exp. Bot. 43: 1191-1198. http://dx.doi.org/10.1093/jxb/43.9.1191

López-Gómez R, Cabrera-Ponce JL, Saucedo-Arias LJ, Carreto-Montoya L, et al. (2009). Ripening in papaya fruit is altered by ACC oxidase cosuppression. Transgenic Res. 18: 89-97. http://dx.doi.org/10.1007/s11248-008-9197-0

Lutts S, Kinet JM and Bouharmont J (1996). Ethylene production by leaves of rice (Oryza sativa L.) in relation to salinity tolerance and exogenous putrescine application. Plant Sci. 1: 15-25. http://dx.doi.org/10.1016/0168-9452(96)04379-8

Mirica LM and Klinman JP (2008). The nature of O2 activation by the ethylene-forming enzyme 1-aminocyclopropane1-carboxylic acid oxidase. Proc. Natl. Acad. Sci. USA 105: 1814-1819. http://dx.doi.org/10.1073/pnas.0711626105

Moeder W, Barry CS, Tauriainen AA, Betz C, et al. (2002). Ethylene synthesis regulated by biphasic induction of 1 -aminocyclopropane-1-carboxylic acid synthase and 1-aminocyclopropane-1-carboxylic acid oxidase genes is required for hydrogen peroxide accumulation and cell death in ozone-exposed tomato. Plant Physiol. 130: 19181926. http://dx.doi.org/10.1104/pp.009712

Nie X, Singh RP and Tai GCC (2002). Molecular characterization and expression analysis of 1-aminocyclopropane-1carboxylate oxidase homologs from potato under abiotic and biotic stresses. Genome 45: 905-913. http://dx.doi. org $/ 10.1139 / \mathrm{g} 02-062$

Genetics and Molecular Research 15 (4): gmr15049034 
Pan G and Lou C (2008). Isolation of an 1-aminocyclopropane-1-carboxylate oxidase gene from mulberry (Morus alba L.) and analysis of the function of this gene in plant development and stresses response. J. Plant Physiol. 165: 12041213. http://dx.doi.org/10.1016/j.jplph.2007.02.012

Petersen TN, Brunak S, von Heijne G and Nielsen H (2011). SignalP 4.0: discriminating signal peptides from transmembrane regions. Nat. Methods 8: 785-786. http://dx.doi.org/10.1038/nmeth.1701

Ruduś I, Sasiak M and Kępczyński J (2013). Regulation of ethylene biosynthesis at the level of 1-aminocyclopropane-1carboxylate oxidase (ACO) gene. Acta Physiol. Plant. 35: 295-307. http://dx.doi.org/10.1007/s11738-012-1096-6

Ski JKP and Ska EKP (2005). Manipulation of ethylene biosynthesis. Acta Physiol. Plant. 27: 213-220. http://dx.doi. org/10.1007/s11738-005-0025-3

Tang X, Wang H, Brandt AS and Woodson WR (1993). Organization and structure of the 1-aminocyclopropane-1carboxylate oxidase gene family from Petunia hybrida. Plant Mol. Biol. 23: 1151-1164. http://dx.doi.org/10.1007/ BF00042349

Teng K, Chang ZH, Xiao GZ, Guo WE, et al. (2016). Molecular cloning and characterization of a chlorophyll degradation regulatory gene (ZjSGR) from Zoysia japonica. Genet. Mol. Res. 15: 4. http://dx.doi.org/10.4238/gmr.15028176

Wan L, Zhang J, Zhang H, Zhang Z, et al. (2011). Transcriptional activation of OsDERF1 in OsERF3 and OsAP239 negatively modulates ethylene synthesis and drought tolerance in rice. PLoS One 6: e25216. http://dx.doi. org/10.1371/journal.pone.0025216

Wang KL, Li H and Ecker JR (2002). Ethylene biosynthesis and signaling networks. Plant Cell 14 (Suppl): S131-S151.

Yang SF and Hoffman NE (1984). Ethylene biosynthesis and its regulation in higher plants. Annu. Rev. Plant Physiol. 35: 155-189. http://dx.doi.org/10.1146/annurev.pp.35.060184.001103

Yang Y, Li R and Qi M (2000). In vivo analysis of plant promoters and transcription factors by agroinfiltration of tobacco leaves. Plant J. 22: 543-551. http://dx.doi.org/10.1046/j.1365-313x.2000.00760.x

Young TE, Meeley RB and Gallie DR (2004). ACC synthase expression regulates leaf performance and drought tolerance in maize. Plant J. 40: 813-825. http://dx.doi.org/10.1111/j.1365-313X.2004.02255.x

Zarembinski TI and Theologis A (1994). Ethylene biosynthesis and action: a case of conservation. Plant Mol. Biol. 26: 1579-1597. http://dx.doi.org/10.1007/BF00016491

Zhang M, Yuan B and Leng P (2009). The role of ABA in triggering ethylene biosynthesis and ripening of tomato fruit. $J$. Exp. Bot. 60: 1579-1588. http://dx.doi.org/10.1093/jxb/erp026

Zhang X, Ervin EH and Schmidt RE (2003). Physiological effects of liquid applications of a seaweed extract and a humic acid on creeping bentgrass. J. Am. Soc. Hortic. Sci. 128: 492-496.

Zhang Z, Ren JS, Clifton IJ and Schofield CJ (2004). Crystal structure and mechanistic implications of 1-aminocyclopropane1-carboxylic acid oxidase - the ethylene-forming enzyme. Chem. Biol. 11: 1383-1394. http://dx.doi.org/10.1016/j. chembiol.2004.08.012

Genetics and Molecular Research 15 (4): gmr15049034 